\title{
Propuesta de adeCuACión para OptimizaCión del Sistema De Seguridad Industrial y Salud Ocupacional en el Área Operativa del Simulador de Vuelo
}

a norma OHSAS 18001, expone los ele-mentos estructurales de un Sistema de Gestión de Prevención de Riesgos Laborales para revisar, gestionar y mejorar el control de los riesgos laborales; y se toma como referencia para los procesos y procedimientos que se llevan a cabo en el simulador de vuelo, para conocer si éste se encuentra en las condiciones óp-

timas de ser certificado.

En
De ahí, que el enfoque teórico consistió en un análisis de las OHSAS 18001, que es un estándar de calidad de prevención de los riesgos laborales que incluye controles y requisitos que facilitan a la empresa el cumplimiento de la legislación aplicable de un proceso de mejora continua; por esto se pueden aplicar a cualquier tipo de empresa, organización y actividad. Igualmente, se tuvo en cuenta los requerimientos legales que van desde la Constitución, el Código del Trabajo, la Ley 100 de Seguridad Social hasta los Decretos 614 de 1984, la Resolución 1016 de 1989 y el Decreto 1295 de 1994, que obligan a los empleadores a asegurar a los trabajadores contra los riesgos profesionales y que se adopten y desarrollen un programa de salud ocupacional.

Asimismo, se realizó una investigación descriptiva para conocer las condiciones en seguridad industrial y salud ocupacional de los usuarios finales del simulador de vuelo FRASCA 242T, de tal forma que se determinó las necesidades y opiniones de quienes utilizan esta herramienta en la Fuerza Aérea. Es por esto que se realizó una evaluación integral del resultado de las entrevistas estructuradas donde se evidenciaron las variables para aplicar una matriz DOFA y se efectuó el cruce de variables de carácter cualitativo.

Los resultados de estos procedimientos demostraron que en el área donde operaba el simulador de vuelo no se acercaba a este contex-

to se planteó la siguiente

pregunta:¿Cómo implementar la propuesta de adecuación del área donde opera el simulador de vuelo FRASCA 242T con el fin de lograr los estándares de calidad necesarios según la norma OHSAS 18001 ?. 
los estándares de calidad para cumplir con la norma OHSAS 18001, ya que existen falencias en la adecuación física para el funcionamiento de la salud ocupacional de los oficiales que trabajan en esta área, porque

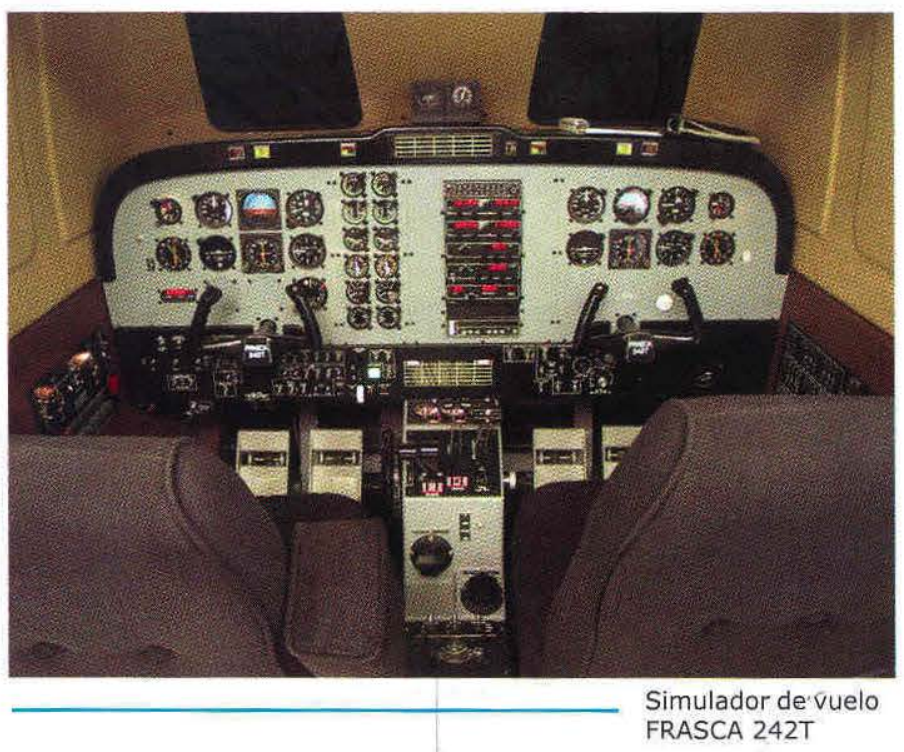
a islamiento del ruido del área de maniobras a través de un vidrio de seguridad especial. Además revisionesmédicas semestrales para el personal con el estudio visual y auditivo en el area no existen divisiones en las secciones de trabajo; el área operativa y la de maniobra se encuentran ubicadas en un solo entorno físico que ocasiona distracción a los alumnos en el momento de la instrucción; la señalización que existe en el simulador no es adecuada, no existe un aula adecuaba y el espacio físico es un corredor, no existen puestos de trabajo suficientes para desempeñarse, y la única puerta de acceso al simulador de vuelo es a través del aula de instrucción, lo que impide una adecuada instrucción.

Lo anterior llevó a los autores a realizar las recomendaciones para la optimización del sistema de seguridad industrial y ocupacional en el área operativa del simulador de vuelo FRASCA 242T de CATAM, de acuerdo con la Norma OHSAS 18001.

Para el área de instrucción se recomienda la señalización adecuada, construcción y adecuación de un salón con mayor capacidad de alumnos en condiciones óptimas de iluminación, instalaciones electrónicas, sillas ergonómicas y mesas de trabajo.

En operaciones se deberá hacer una señalización adecuada, un ambiente de temperatura para los equipos de cómputo que operan en el simulador por medio de aire acondicionado, iluminación focalizada, de maniobras; en el simulador de vuelo colocar aire acondicionado, un plan de iluminación para el oscurecimiento de la sala, aislamiento

del ruido del área de maniobras $y$ un sistema de iluminación $y$ audífonos compati bles con el IDENTIFICACIÓN GENERAL DEL PROYECTO PROGRAMA ESPECIALIZACIÓN EN GERENCIA DE LAA TÍTULO PROPUESTA DE ADECUACIÓN PARA OPTIMIZACIÓN DEL SISTEMA DE SEGURIDAD INDUSTRIAL Y SALUD OCUPACIONAL EN EL ÁREA OPERATIVA DEL SIMULADOR DE VUELO simulador. Asimismo, un mejor sis te ma de seguridad industrial con la AUTORES

construcción de una

\section{LINNEA DE} INVESTIGACIÓN MY. CÉSAR AUGUSTO ACERO GÓMEZ ST. MAGDA JINETTE RINCÓN RIVERA puerta para la evacuación directa y revisiones periódicas de los niveles del ruido

Finalmente, los aportes de este estudio van encaminados en un futuro a lograr la certificación de calidad del simulador de vuelo. 